Article

\title{
Surface Modification of Carbon Microspheres with Guanidine Phosphate and Its Application as a Flame Retardant in PET
}

\author{
Shan Jiang * $\mathbb{0}$, Cheng Ji, Dan Zha, Yonghong Ding, Dun Wu and Qiang Yu
}

School of Materials Science and Engineering, Jiangsu Collaborative Innovation Center for Photovolatic Science and Engineering, Changzhou University, Changzhou 213614, China; 18000151@smail.cczu.edu.cn (C.J.); zhadan@toray-tpn.cn (D.Z.); dyh@cczu.edu.cn (Y.D.); wudun@cczu.edu.cn (D.W.); yuqiang@cczu.edu.cn (Q.Y.)

* Correspondence: Jiangshan@cczu.edu.cn

Received: 28 June 2020; Accepted: 26 July 2020; Published: 29 July 2020

\begin{abstract}
Composites based on polyethylene terephthalate (PET) and surface-modified carbon microspheres (CMSs) were prepared by melt mixing. The surface modification of CMSs was conducted with low-temperature plasma technology first, and a phosphorus-nitrogen flame retardant, guanidine phosphate (GDP), was then grafted onto CMSs. The modification of CMSs was done to improve both the filler dispersity in the PET matrix and the flame-retardant performance of composites. The obtained CMSs-GDP was characterized by FTIR spectra and a scanning electron microscope (SEM). The grafting ratio was characterized and calculated by thermal gravimetric analysis (TGA). The grain size analysis was used to describe the dispersity of CMSs. The mechanical properties of the PET/CMSs-GDP composite were measured using a universal testing machine. The PET/CMSs-GDP composite can achieve a limiting oxygen index (LOI) value of $32.4 \%$ and a vertical burning test (UL94) V-0 rating at $3 \%$ CMSs-GDP loading.
\end{abstract}

Keywords: PET; carbon microspheres; flame retardant; guanidine phosphate; surface modification

\section{Introduction}

Flame retardants for polyethylene terephthalate (PET) have been a constant research hotspot. The commonly reported flame retardants used with PET can be divided into various kinds, such as traditional halogen-containing flame retardants, intumescent flame retardants, and inorganic nanometer fire retardants [1]. However, with recent stricter requirements for safety and environmental protection, the development of halogen flame retardants has been limited [2]. Many new inorganic nanometer halogen-free and intumescent flame retardants have been synthesized [3]. For example, Cai [4] studied the effects of laminated metal lanthanum phenyl phosphonate (LaPP) on the thermal stability, flame retardation characteristics, and mechanical properties of a PET/microcapsule red phosphorus system (PET/GF-MRP) reinforced by glass fiber, whose LOI can reach $28.9 \%$. Wu [5] used liquid bisphenol A, double (diphenyl phosphorous) (BDP) to pre-disperse, so that carbon nanotubes could be dispersed uniformly in PET by melting and blending, which can enhance the flame-retardant behavior. Feng [6] incorporated a flame-retardant system consisting of 1-hydroxymethyl-1, 1-diphosphate (HEDP) and ammonium sulfamate into polyester fabric for flame retardation; the LOI was increased to $28 \%$, and the results showed that the PET composite material can achieve the UL94-V0 level.

Carbon microspheres are a new type of nano-inorganic carbon material that have received much attention recently [7]. CMSs have been widely studied because of their excellent heat resistance, chemical stability, and good electrical and thermal conductivity [8]. However, CMSs are bonded by means of a strong $\pi-\pi$ conjugated system and van der Waals forces, so their particulates are markedly 
clustered and their dispersion in matrix material is poor [9]. Therefore, the modification of dispersion and interface compatibility of CMSs has received emphasis at this stage. The most common modification method of CMSs is chemical pretreatment with sulfuric acid $\left(\mathrm{H}_{2} \mathrm{SO}_{4}\right)$ and nitric acid $\left(\mathrm{HNO}_{3}\right)$ to modify the surface of carbon microspheres [10,11]. Qi [12] used sulfuric acid and nitric acid to modify carbon spheres, and their dispersion and interface compatibility were improved. Eon [13] synthesized a sulfur/graphitic hollow carbon sphere to improve the surface of carbon spheres; the carbon spheres were prepared from pyrolysis of a homogenous mixture of monodispersed spherical silica, and their dispersion was modified significantly. Recently, the application of CMSs in flame-retardant material has received attention [14]. CMSs can expand when heated, making them a new additive intumescent flame retardant [14]. When a composite material is burned, the CMSs can expanded to a porous structure, which can obstruct the combustible gas; thus, they have flame-resistant effects $[15,16]$. For example, Yaru [17] used MH@CMSs to microencapsulate PET to obtain microencapsulated CMSs coated by magnesium hydroxide flame retardants; the LOI of the composite material was enhanced to $27.4 \%$. Niu [7] added CMSs coated with magnesium hydroxide $\left(\mathrm{Mg}(\mathrm{OH})_{2} @ \mathrm{CMSs}\right)$ to PET to improve the flame retardancy of PET, with an LOI that reached $27.5 \%$.

The aim of the present work is to synthesize a graft-modified CMSs flame retardant, called CMSs-GDP, with high flame retardant efficiency and good mechanical properties. The chemical structure of CMSs-GDP was characterized by FTIR, XRD, and TGA. The dispersion and interface compatibility were characterized by grain size analysis and SEM. The flame retardant and mechanical properties were comprehensively investigated.

\section{Experimental}

\subsection{Material and Instruments}

Beta-cyclodextrin and guanidine phosphate were purchased from Aladdin Chemical Reagent Corp. (Shanghai, China). Carbon microspheres were synthesized from beta-cyclodextrin by hydrothermal synthesis. PET resin (CR-8663) was purchased from Changzhou Huarun Chemical Holdings Co., Ltd. (Changzhou, China). Other chemicals were purchased from China National Pharmaceutical Group (Shanghai, China). The low-temperature plasma processor (WAOL 2000-Cr) was acquired from Suzhou Qianxun Electronics Co., Ltd. (Suzhou, China).

The synthesis and Preparation of CMSs, CMSs-PLS, and CMSs-GDP is shown in Figure 1.

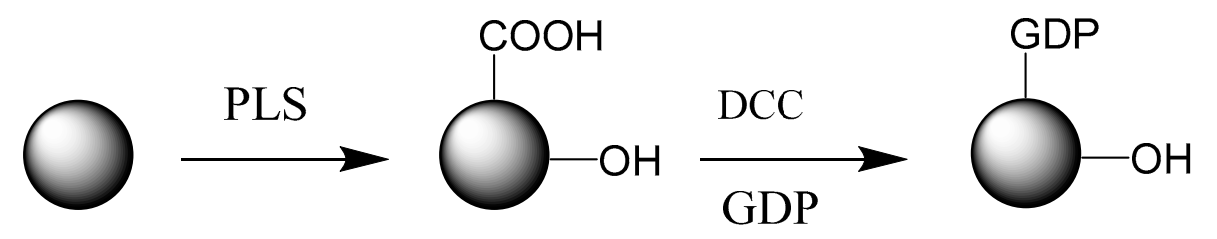

\section{CMSs-PLS}

CMSs-GDP

Figure 1. Synthesis of graft-modified carbon microspheres (DCC: Dicyclohexylcarbodiimide; GDP: $\mathrm{C}_{2} \mathrm{H}_{10} \mathrm{~N}_{6} \bullet \mathrm{H}_{3} \mathrm{PO}_{4}$ ).

Carbon microspheres were compounded by the hydrothermal synthesis of cyclodextrin. The hydrothermal synthesis temperature and time were $160^{\circ} \mathrm{C}$ and $10 \mathrm{~h}$, respectively. Low-temperature plasma technology was adopted to modify the surface of CMSs, giving birth to CMSs-PLS; the low-temperature plasma time is set to $300 \mathrm{~s}$ and the power is $250 \mathrm{~W}$. A phosphorus-nitrogen flame retardant, guanidine phosphate (GDP), was grafted onto CMSs by impregnating and grafting (see Figure 1) to improve the flame retardant characteristics, interface compatibility, and dispersity of 
CMSs; the resulting material was named CMSs-GDP. The main chemical reaction is the amidation of the amine group and the alkyl group on the CMS.

\subsection{Preparation of Composite Material}

PET/CMSs-GDP composites were prepared using an Internal Mixer (model PPT-3/ZZL-40, Mester Industrial System, Shanghai, China) rotating at $40 \mathrm{r} / \mathrm{min}$ and a mixing chamber with the capacity to hold $45 \mathrm{~g}$ of material. Composites with $0,1,2$, and $3 \mathrm{wt} \%$ of CMSs-GDP were prepared. The mixing temperature was monitored using a thermocouple and reached $260^{\circ} \mathrm{C}$ in $5 \mathrm{~min}$ of mixing. The compositions were named according to the content of CMSs-GDP, for example, the composite with the addition of $1 \mathrm{wt} \%$ of CMSs-GDP is referred to as PET/1\%CMSs-GDP.

\subsection{Characterization of Composite Material}

The thermal properties of the composites were determined by thermal gravimetric analysis (TGA). The TGA equipment used was a TA Instruments QS100 calorimeter (TA Instruments, New Castle, state abbreviation, USA), and the analysis was conducted under $\mathrm{N}_{2}$ atmosphere. The PET/CMSs-GDP composite was analyzed according to the following procedures; samples were heated to $800{ }^{\circ} \mathrm{C}$ at $10{ }^{\circ} \mathrm{C} \mathrm{min}^{-1}$.

TGA-FTIR was carried out to characterize the flame-retardant mechanism of composite material.

To analyze the fracture surface morphology of the composites by SEM, the sample was fracture in liquid nitrogen and were cryogenically fractured and coated with a thin layer of gold. The fracture surface was observed under an SEM FEI Inspect S50 (FEI, Portland, OR, USA), operating at $15 \mathrm{keV}$.

The vertical burning was tested by UL-94 flame chamber (Dongguan City Star Joe Equipment Co., Ltd., Dongguan, China) according to ASTMD 3801-2010 standard. The samples were processed in a size of $130 \mathrm{~mm} \times 10 \mathrm{~mm} \times 3 \mathrm{~mm}$ and fixed vertically above a cotton patch during tests.

The charred residue structure was obtained by the Hitachi X650 scanning electron microscopy (SEM, Hitachi Limited, Tokyo, Japan). Moreover, the combustion performance was measured using the HC-2 oxygen index meter (Dongguan Toyo Machinery Co., Ltd., Dongguan, China), according to the ASTM D2863 standard procedures.

The tensile properties were measured using a WD20D electronic universal tester (Jintan Medical Instrument Factory, Changzhou, China) according to ISO527 standard. The samples were processed in a size of $25 \mathrm{~mm} \times 4 \mathrm{~mm} \times 2 \mathrm{~mm}$, and the crosshead speed is set to $400 \mathrm{~mm} \mathrm{~min}^{-1}$.

\section{Results and Discussion}

\subsection{Characterization of CMSs}

FTIR was used to investigate the chemical structure of carboxyl and hydroxyl groups in CMSs. It can be seen in Figure 2 that the absorption band of carboxyls and hydroxyls is evident for CMSs-PLS. From Figure 2, the characteristic absorption band at $3390 \mathrm{~cm}^{-1}$ is the stretching vibration peak of hydroxyl. The characteristic absorption band at $1662 \mathrm{~cm}^{-1}$ is the stretching vibration peak of carboxyl, and the characteristic absorption band at $1031 \mathrm{~cm}^{-1}$ is the bending vibration peak of carboxyl [18]. Thus, carboxyl and hydroxyl were proved to be grafted onto CMSs by means of low-temperature plasma technology. Figure 2 clearly shows that the GDP was chemically grafted onto the CMSs by impregnation. Some characteristic absorption bands were present in the FTIR spectrum of graft-modified CMSs. The characteristic absorption band at $3411 \mathrm{~cm}^{-1}$ is the $\mathrm{N}-\mathrm{H}$ stretching vibration peak of amide bonds. The characteristic absorption band at $1666 \mathrm{~cm}^{-1}$ is the $\mathrm{C}=\mathrm{O}$ in-plane flexural vibration peak of amide bonds. The characteristic absorption band at $1093 \mathrm{~cm}^{-1}$ is the $\mathrm{P}-\mathrm{O}$ stretching vibration peak of the phosphate group. 


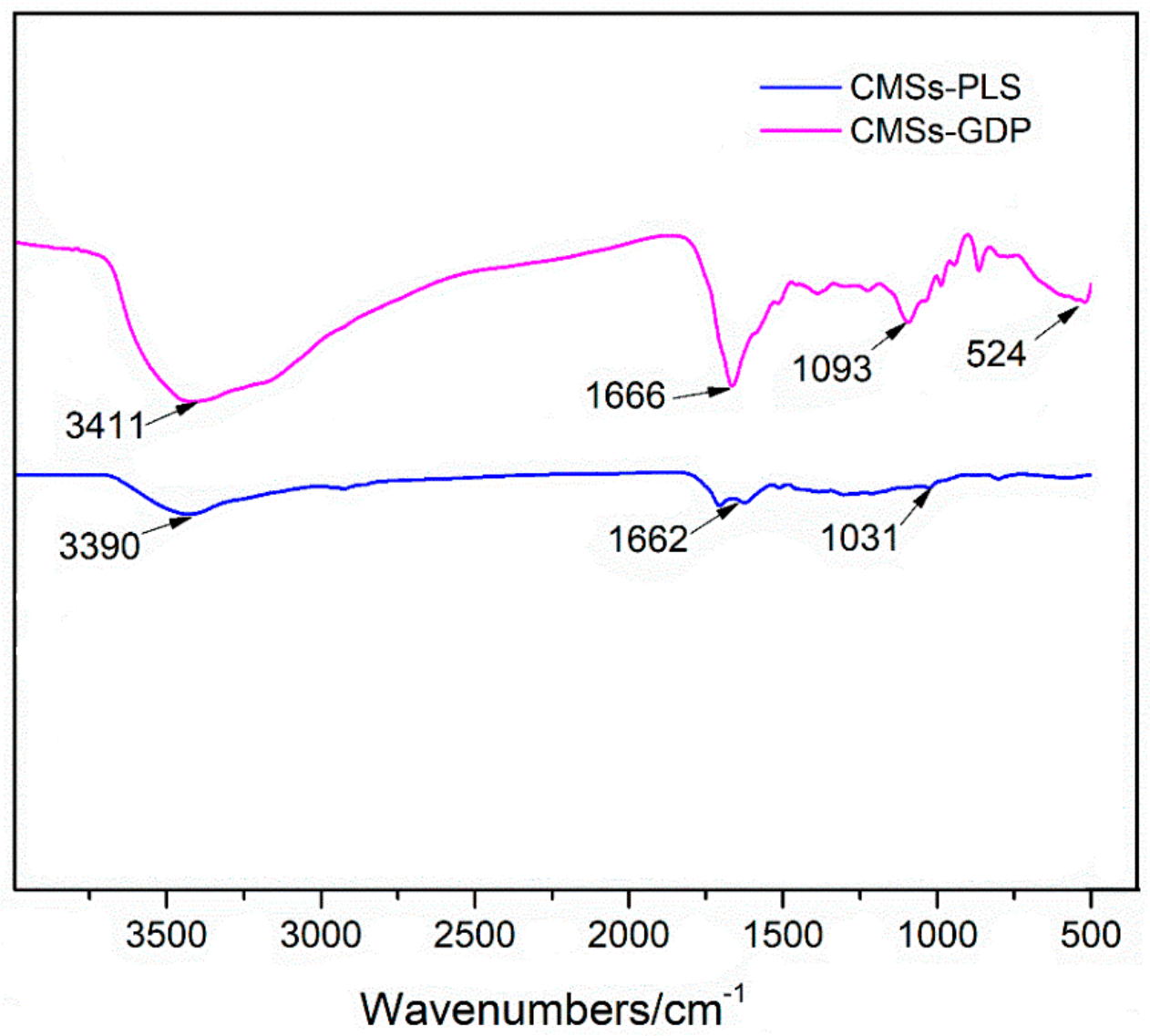

Figure 2. FTIR of CMSs-PLS and CMSs-GDP.

Raman spectroscopy can be used to characterize the structural defects of CMSs. In Figure 3, which shows the Raman spectra of modified CMSs, there are two characteristic absorption bands. The characteristic absorption band at 1583 is the characteristic peak of $\mathrm{sp}^{2}$ carbon atoms, called the $\mathrm{G}$ peak, and the characteristic absorption band at 1374 is the characteristic peak of defects of carbon atoms, called the D peak [19]. The existence of the D peak (Figure 3) demonstrates that the original $\mathrm{sp}^{2}$ hybridization of the system was damaged. This result suggests that carboxyl and hydroxyl groups were grafted onto the CMSs by the low-temperature plasma treatment, which can destroy the $\mathrm{sp}^{2}$ hybridization of the original system. The $\mathrm{I}(\mathrm{D}) / \mathrm{I}(\mathrm{G})$, the peak ratio between the $\mathrm{D}$ peak and the $\mathrm{G}$ peak, represents the relationship between the two characteristic peaks [20]. A greater value of $I(D) / I(G)$ denotes more crystal defects in the carbon atom. The $\mathrm{I}(\mathrm{D}) / \mathrm{I}(\mathrm{G})$ of CMSs-GDP was 0.54 , more than the value of CMSs-PLS and CMSs, which represents that GDP was grafted on the surface of CMSs.

Grain size analysis was used to provide the degree of dispersion of CMSs. The polydispersity coefficient (PDI) (Table 1) is a key parameter of grain size analysis that can be used to characterize the dispersion of a material [21]. A lower PDI means the stability and the dispersity of a material are better. On the contrary, a higher PDI means the stability and dispersity of a material are poor. The grain size of CMSs-PLS with discharge power of $250 \mathrm{~W}$ and processing time of 5 min was $343 \mathrm{~nm}$, which was suitable and uniformitarian. However, the same batch of CMSs-PLS shows different grain size; this was caused by different discharge power and time. When the discharge power is lower than $250 \mathrm{~W}$, the CMSs cannot be completely modified, which can lead to the reunion of CMSs, so the grain size was larger. When the discharge power is higher than $250 \mathrm{~W}$, the structure of CMSs was broken into char residue, which cannot be dispersed in solution, so the grain size was larger [22]. Therefore, as suggested by the results in Table 1, a discharge power of $250 \mathrm{~W}$ and processing time of $5 \mathrm{~min}$ led to the best chemical modification of CMSs-PLS. 


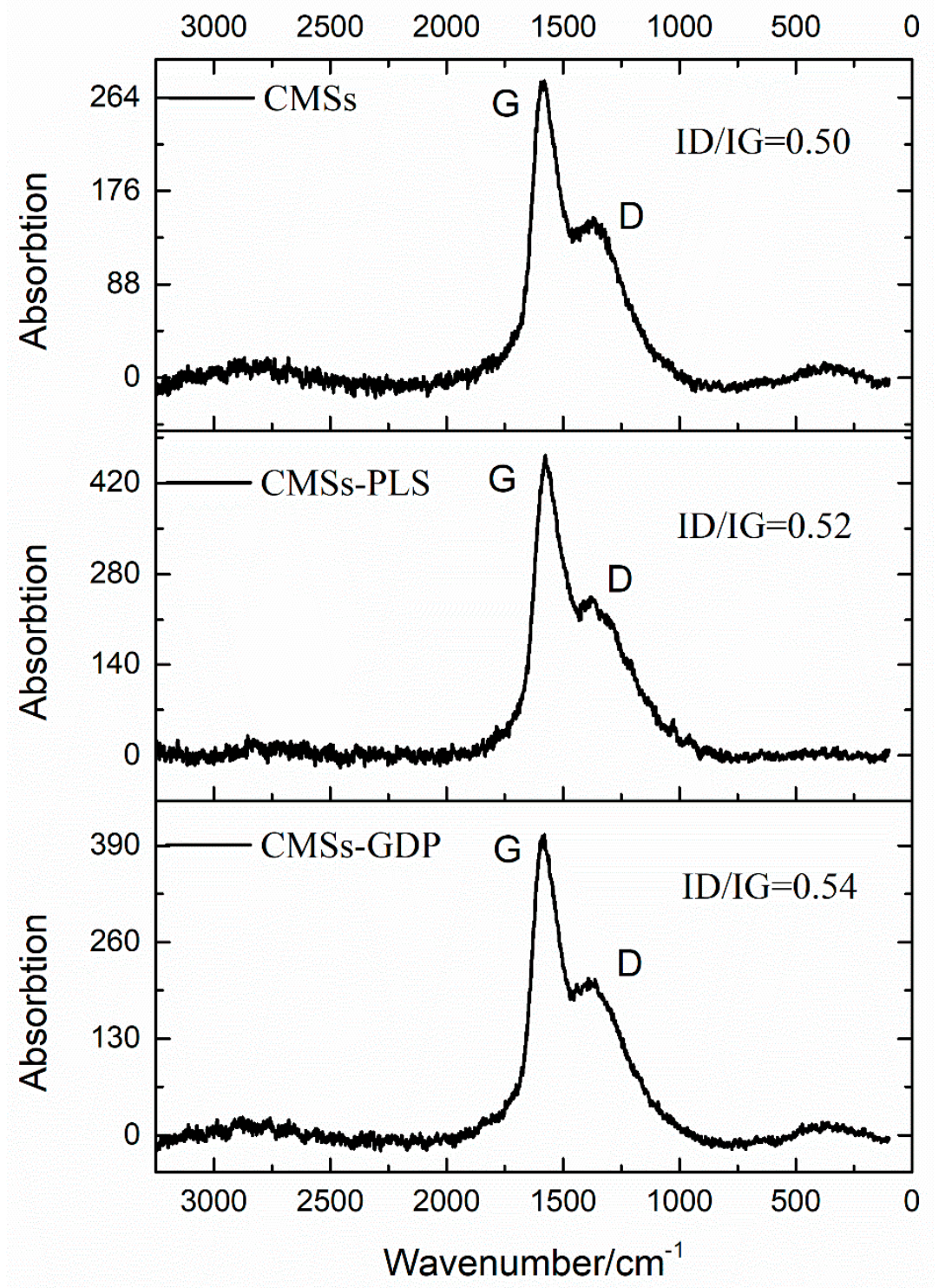

Figure 3. Raman spectrum of CMSs, CMSs-PLS, and CMSs-GDP.

Table 1. Grain size analysis of CMSs-PLS in ethyl alcohol solution.

\begin{tabular}{cccc}
\hline Discharge Power/W & Time/min & Grain Size/nm & PDI \\
\hline 200 & 5 & 574 & 1.00 \\
250 & 5 & 343 & 0.58 \\
300 & 5 & 632 & 1.00 \\
250 & 10 & 264 & 0.66 \\
250 & 15 & 439 & 0.80 \\
\hline
\end{tabular}

Figures 4 and 5 provide further evidence that the GDP was chemically grafted onto the CMSs. Thermogravimetric analysis (TGA) was utilized to calculate the grafting ratio of the GDP onto CMSs [23]. The grafting ratio can be calculated by means of the difference in the weight losses at the various characteristic peaks. There were two characteristic peaks on the derivative thermogravimetry (DTG) curve of CMSs (Figures 4 and 5). Generally, the peak at $60^{\circ} \mathrm{C}$ is the water peak, which is generated by the moisture loss from raw CMSs. The peak at $429^{\circ} \mathrm{C}$ is the weight loss peak of CMSs. However, in Figure 5, in addition to the two typical peaks, a new peak at approximately from $270{ }^{\circ} \mathrm{C}$ to $350{ }^{\circ} \mathrm{C}$ can be seen; these are the weight loss peaks of grafted GDP, and it proves that the GDP unit was chemically 
grafted onto the CMSs and the grafting ratio of CMSs-GDP can reach to $10.73 \%$. In conclusion, the GDP was successfully grafted onto the surface of CMSs.

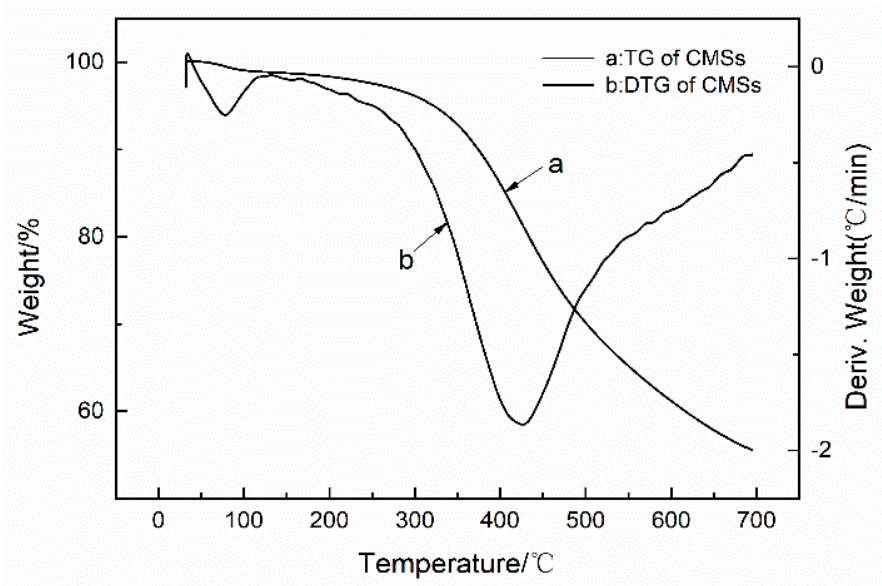

Figure 4. TG and DTG of carbon microspheres.

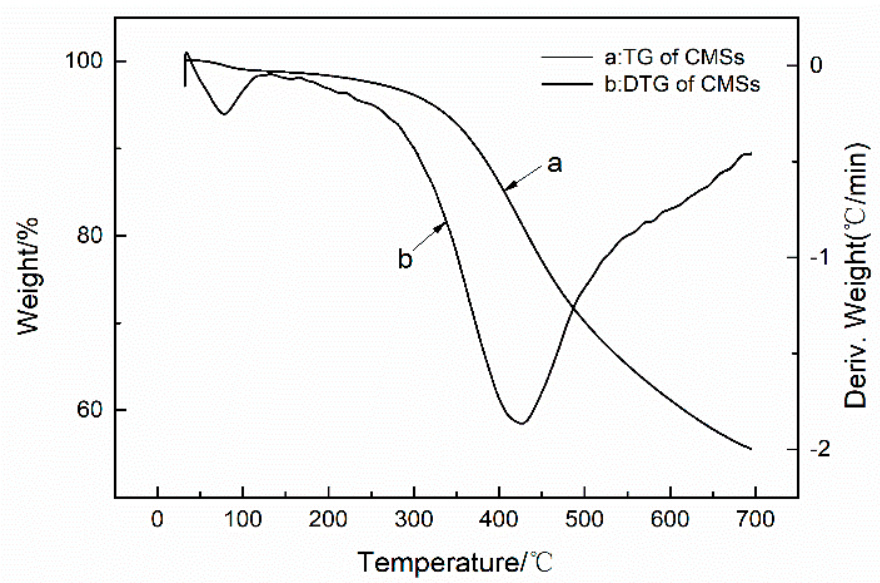

Figure 5. Thermal gravimetry (TG) and derivative thermogravimetry (DTG) of CMSs-GDP.

\subsection{Flammability of PET and Composite Materials}

In Table 2, $\mathrm{t} 1$ represents the residual flame time of first combustion, $\mathrm{t} 2$ represents the residual flame time of second combustion, and $\mathrm{t} 3$ represents the flame spark resident time of second combustion. It is easily shown that the flame retardant behavior of pure PET is poor, and its rating is the HB, according to the UL94-V test. After the addition of CMSs-GDP, $\mathrm{t} 1$ and $\mathrm{t} 2$ are both less than $10 \mathrm{~s}, \mathrm{t} 1+\mathrm{t} 2$ is less than $30 \mathrm{~s}$, and $\mathrm{t} 2+\mathrm{t} 3$ is less than $10 \mathrm{~s}$, which all conform to the UL94-V0 rating. Simultaneously, the samples all underwent incomplete combustion, and the droppings did not ignite cotton wool. As a result, the composite material achieves the UL94-V0 rating, with flame-retardant behavior that is markedly better than that of pure PET. With an increase in the amount of CMSs, the flame-retardant behavior of the composite material is much more effective.

As a kind of flame retardant, CMSs can form a substrate surface protective layer during combustion, which has the effect of heat insulation and oxygen insulation. Meanwhile, flammable gas and heat transfer were also prevented by CMSs, which can interrupt combustion and enhance the flame retardant behavior of the composite material.

As an intumescent flame retardant, three elements must be provided: the carbon source, the air source, and the acid source. CMSs with hydroxy groups can provide the carbon source, founding a compact carbon layer, making heat difficult to penetrate the condensed phase, preventing oxygen from entering the combustion zone, and preventing the degradation of the gas on the surface of the 
material. The phosphorus-nitrogen flame retardant GDP can provide the acid source and air source: GDP combined with PET will thermally decompose phosphoric acid, phosphoric anhydride, and other substances during combustion. Phosphoric acid will be further dehydrated to form metaphosphoric acid and pyrophosphoric acid, which will produce oxygen-containing polymer to form a dense carbon layer during PET decomposition. GDP combined with PET will thermally decompose non-flammable gases such as $\mathrm{NH}_{3}$ and $\mathrm{NO}_{2}$, which can dilute combustible gas, and play a flame-retardant role in the gas phase. Simultaneously, CMSs become an inorganic residue by expanding when heated. Thus, the flame retardant characteristics of the matrix material can be improved.

Table 2. Vertically burning analysis of polyethylene terephthalate (PET) composites.

\begin{tabular}{cccccccc}
\hline Sample & $\mathbf{t} 1 / \mathbf{s}$ & $\mathbf{t} 2 / \mathbf{s}$ & $\mathbf{t 3} / \mathbf{s}$ & $\mathbf{t 1 + t}$ /s & $\mathbf{t} 2+\mathbf{t}$ 3/s & Melt Drip & $\begin{array}{c}\text { Complete } \\
\text { Combustion }\end{array}$ \\
\hline 100\%PET & 15.77 & 15.74 & 0.4 & 31.51 & 16.14 & $\mathrm{Y}$ & $\mathrm{Y}$ \\
99\%PET/1\%CMSs & 9.64 & 10.57 & 0.5 & 20.21 & 11.07 & $\mathrm{Y}$ & $\mathrm{Y}$ \\
98\%PET/2\%CMSs & 6.45 & 6.72 & 0.3 & 13.17 & 7.02 & $\mathrm{Y}$ & $\mathrm{Y}$ \\
97\%PET/3\%CMSs & 3.37 & 3.12 & 0.3 & 6.49 & 3.42 & $\mathrm{Y}$ & $\mathrm{N}$ \\
99\%PET/1\%CMSs-PLS & 9.34 & 7.78 & 0.6 & 17.12 & 8.38 & $\mathrm{Y}$ & $\mathrm{Y}$ \\
98\%PET/2\%CMSs-PLS & 4.21 & 5.35 & 0.5 & 9.56 & 5.85 & $\mathrm{Y}$ & $\mathrm{Y}$ \\
97\%PET/3\%CMSs-PLS & 3.21 & 3.44 & 0.2 & 6.65 & 3.46 & $\mathrm{Y}$ & $\mathrm{N}$ \\
99\%PET/1\%CMSs-GDP & 8.72 & 8.36 & 0.4 & 17.08 & 8.76 & $\mathrm{Y}$ & $\mathrm{Y}$ \\
98\%PET/2\%CMSs-GDP & 4.33 & 4.19 & 0.4 & 8.52 & 4.59 & $\mathrm{~N}$ & $\mathrm{~N}$ \\
97\%PET/3\%CMSs-GDP & 2.19 & 3.21 & 0.2 & 5.40 & 3.41 & $\mathrm{~N}$ & $\mathrm{~N}$ \\
\hline
\end{tabular}

\subsection{Thermal Properties and Degradation Mechanism of PET Composite Material}

Figures 6 and 7 show the TGA curves in nitrogen of pure PET and PET/CMSs-GDP composites. The TG and DTG data are listed in Table 3 including the initial decomposition temperature $\left(\mathrm{T}_{5 \%}\right.$ was the temperature of $5 \mathrm{wt} \%$ weight loss), temperature of maximum weight loss $\left(\mathrm{T}_{\max }\right)$, the rate of Tmax and the residue of composites at $800{ }^{\circ} \mathrm{C}$.

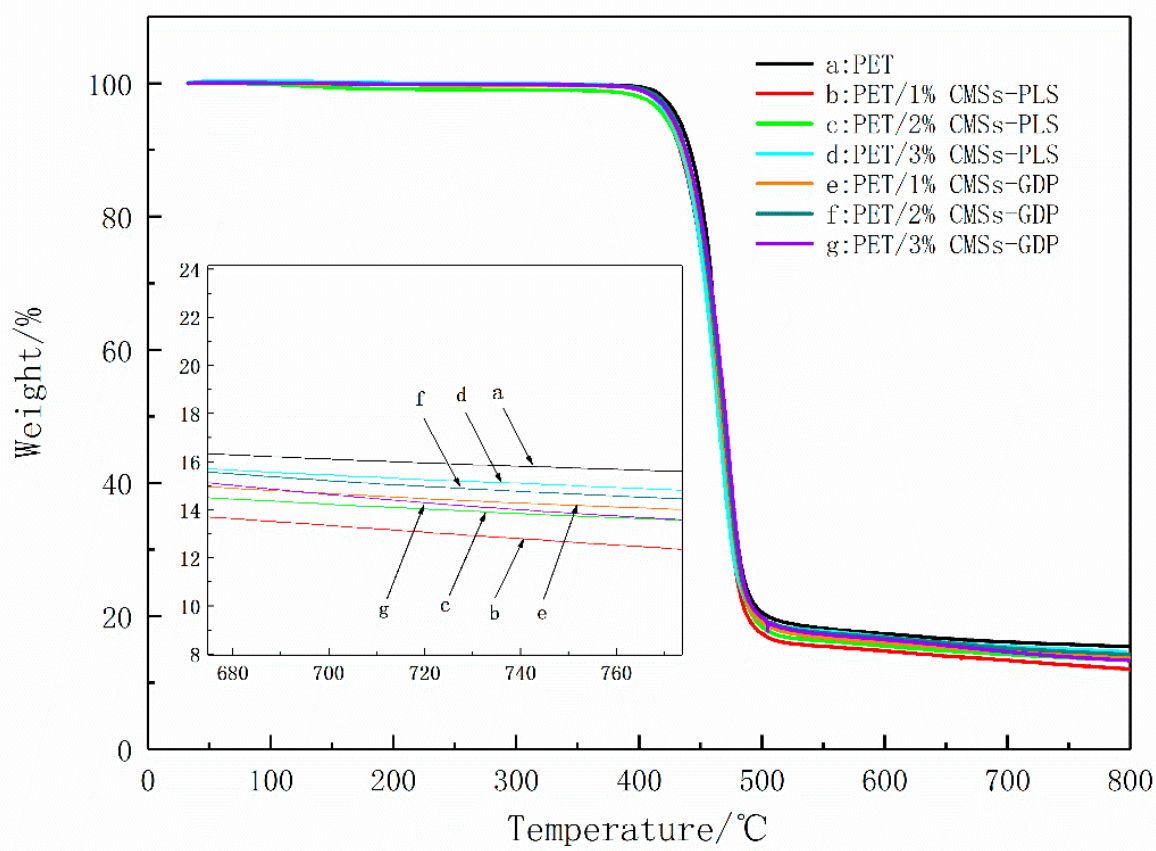

Figure 6. The TG curves of PET, PET/CMSs-PLS, and PET/CMSs-GDP. 


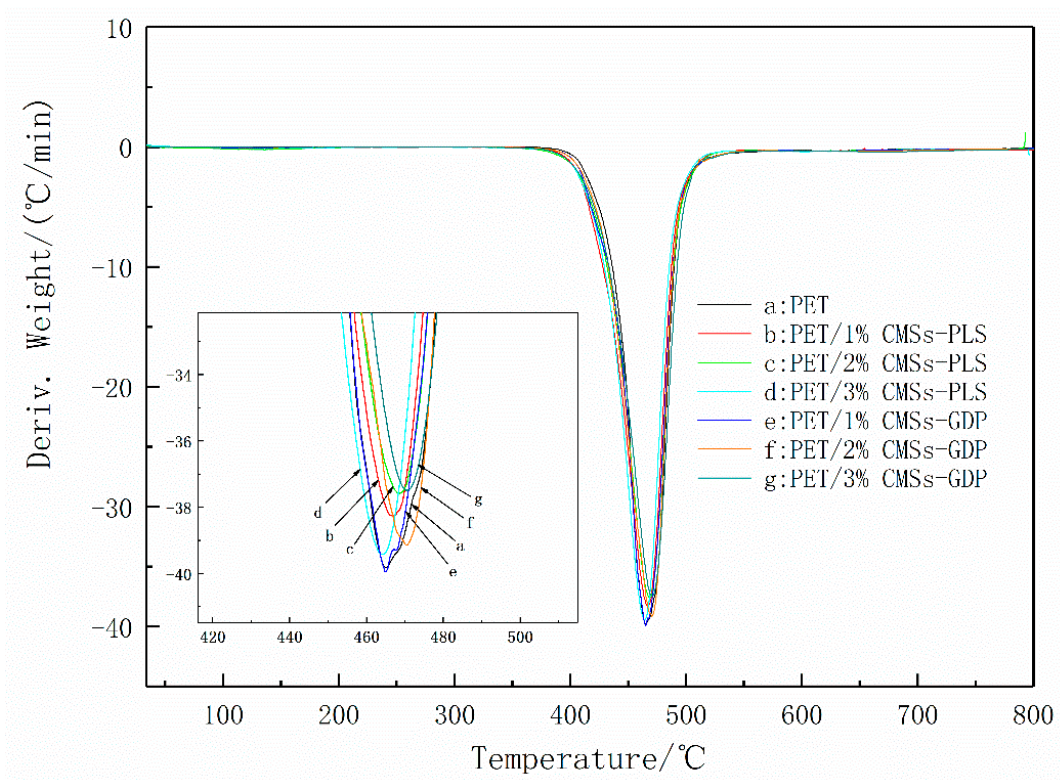

Figure 7. The DTG curves of PET, PET/CMSs-PLS, and PET/CMSs-GDP.

Figures $6 \mathrm{a}$ and $7 \mathrm{a}$ show that the PET begins to decompose at a temperature (T5\%) of $\sim 420{ }^{\circ} \mathrm{C}$, the maximum decomposition temperature Tmax is $464{ }^{\circ} \mathrm{C}$, and the maximum thermal weight loss rate is $39.8 \mathrm{wt} \% \mathrm{~min}^{-1}$. Figures $6 \mathrm{a}$ and $7 \mathrm{a}$ show that when adding $1 \%$ of CMSs, the $\mathrm{T}_{5 \%}$ of the composite increased to $422{ }^{\circ} \mathrm{C}$, and the maximum thermal weight loss rate decreased to $38.2 \mathrm{wt} \% \mathrm{~min}^{-1}$. As the amount of carbon microspheres increased, the initial decomposition temperature could be increased to $426^{\circ} \mathrm{C}$, and the maximum weight loss temperature increased to $468{ }^{\circ} \mathrm{C}$. At the corresponding maximum weight loss rate was reduced to $36.4 \mathrm{wt} \% \mathrm{~min}^{-1}$.

Table 3. TGA data of GDP, CMSs-GDP, PET, and the blends in nitrogen residue.

\begin{tabular}{|c|c|c|c|c|c|c|}
\hline \multirow[t]{2}{*}{ Sample } & \multirow{2}{*}{$\mathrm{T}_{5 \%}\left({ }^{\circ} \mathrm{C}\right)$} & \multicolumn{2}{|c|}{$\mathrm{T}_{\max }\left({ }^{\circ} \mathrm{C}\right)$} & \multicolumn{2}{|c|}{$\begin{array}{l}\text { The rate of } T_{\max } \\
\left(w \mathrm{t} \% \mathrm{~min}^{-1}\right)\end{array}$} & \multirow{2}{*}{$\begin{array}{l}\text { Residue at } 800 \\
{ }^{\circ} \mathrm{C}(\text { wt } \%)\end{array}$} \\
\hline & & Stage 1 & Stage 2 & Stage 1 & Stage 2 & \\
\hline CMSs & 352 & - & 440 & - & 10.8 & 55.31 \\
\hline CMSs-GDP & 221 & 276 & 443 & 1.3 & 2.55 & 44.61 \\
\hline PET & 420 & - & 464 & - & 39.8 & 11.91 \\
\hline PET/1\%CMSs & 422 & - & 464 & - & 38.2 & 13.20 \\
\hline $\mathrm{PET} / 2 \% \mathrm{CMSs}$ & 423 & - & 466 & - & 37.5 & 13.21 \\
\hline PET $/ 3 \% C M S s$ & 426 & - & 468 & - & 36.4 & 13.78 \\
\hline PET/1\%CMSs-GDP & 428 & - & 470 & - & 35.9 & 14.18 \\
\hline PET/2\%CMSs-GDP & 431 & - & 472 & - & 35.1 & 14.65 \\
\hline PET/3\%CMSs-GDP & 435 & - & 473 & - & 34.4 & 15.42 \\
\hline
\end{tabular}

As a result, the addition of carbon microspheres can increase the degradation temperature of PET and reduce the rate of degradation when carbon microspheres were burned, it can be expanded and broken to produce some acidic material and inorganic carbon layer on the surface of PET, which can lead to the reduction of the heat transmission from outside and the fuel gas diffusion from inside. When CMSs-GDP was added, the decomposition temperature and maximum decomposition temperature of the PET composites were further increased, and the thermal weight loss rate was further decreased. When the CMSs-GDP addition amount reached $3 \%$, the $\mathrm{T}_{5} \%$ reached the highest $435^{\circ} \mathrm{C}$, the maximum decomposition temperature increased to $473{ }^{\circ} \mathrm{C}$, and the maximum thermal weight loss rate reduced to $34.4 \mathrm{wt} \% \mathrm{~min}^{-1}$. Thus, the modified CMSs-GDP can further improve the thermal stability of the PET matrix material and reduce combustion. The heat release rate in the process, combined with the flame retardant experimental data, also shows that the introduction of CMSs-GDP can further improve the flame-retardant properties of PET composites. 
In order to further investigate the relationship between the microstructure and flame retardant, the outer surface of thermo-oxidative decomposition char residue of samples at $800{ }^{\circ} \mathrm{C}$ in a muffle furnace for $10 \mathrm{~min}$ under air atmosphere were inspected by SEM, and the micrographs are shown in Figure 8. As shown in Figure 8a,b, there were many big holes and a fragile fractured surface on the pure PET which was not modified after combustion, suggesting a large amount of the heat transmission and gas diffusion. In the cases of PET/1\%CMSs-GDP (see Figure 8c,d), the outer surface of the composite becomes compact and intact, and it can be observed in the structure of CMSs that the size and distribution of holes were reduced. Compared with the pure PET, the crack and the holes was significantly decreased. Carbon microspheres were expanded when heated, then CMSs was fractured to form a substrate surface protective layer during combustion. The inorganic carbon layer was covered on the surface of PET basis material, which can insulate the flammable gas and quality of heat. Due to the flame retardant nature of CMSs-GDP, the heat release rate was reduced and the flame retardant properties of PET were optimized. From Figure 8g,h, it can be observed that the structure of CMSs-GDP was significantly increased and an inorganic carbon layer formed by CMSs-GDP was covered on the surface of PET. This not only effectively protected the internal structure, but also increased the barrier closeness, leading to the reduction of heat transmission from outside and fuel gas diffusion from inside. Then, the non-flammability and high performance of PET/CMSs-GDP were exhibited.

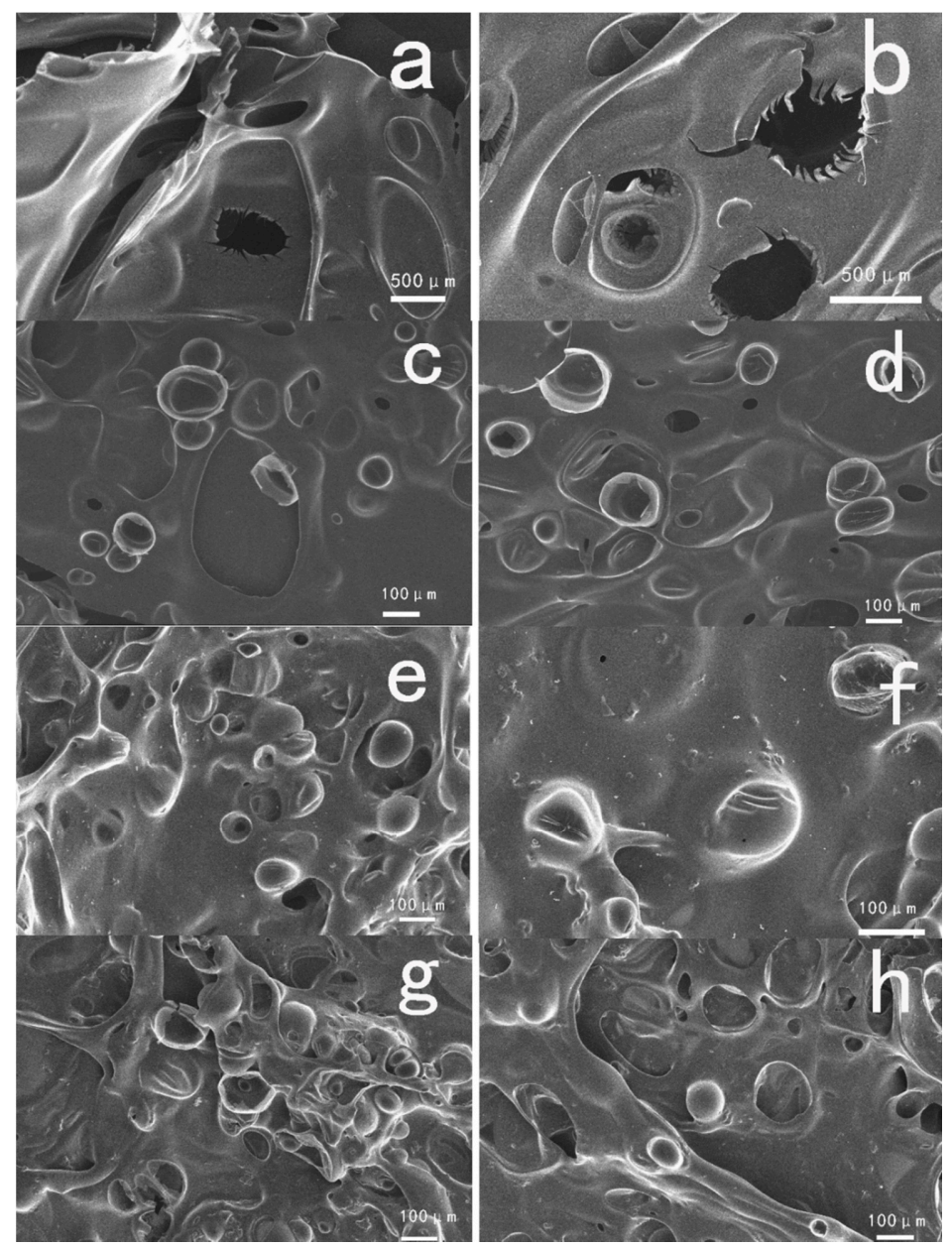

Figure 8. SEM image of PET, PET/1\%CMSs-GDP, PET/2\%CMSs-GDP, and PET/3\%CMSs-GDP at $800{ }^{\circ} \mathrm{C}$ in a Muffle Furnace for 10 min under air atmosphere $((\mathbf{a}, \mathbf{b})$ the outer surface of PET; $(\mathbf{c}, \mathbf{d})$ the outer surface of PET/1\%CMSs-GDP; $(\mathbf{e}, \mathbf{f})$ the outer surface of PET/2\%CMSs-GDP; $(\mathbf{g}, \mathbf{h})$ the outer surface of PET/3\%CMSs-GDP). 
Figures 9-12 show the FTIR of the PET/CMSs-GDP composite at different temperature. It can be seen from Figure 9 that at the beginning of decomposition $\left(\mathrm{T}_{5 \%}\right)$, the characteristic peaks of PET segments are obvious. The characteristic peaks at $2740 \mathrm{~cm}^{-1}$ is the expansion and contraction of $\mathrm{C}-\mathrm{H}$. The characteristic peaks at $1759 \mathrm{~cm}^{-1}$ is the typical stretching vibration peak of $\mathrm{C}=\mathrm{O}$. The peaks at $1263 \mathrm{~cm}^{-1}$ is the characteristic peak of CO-O-C, and the characteristic peak of $\mathrm{C}-\mathrm{O}-\mathrm{C}$ is at $1091 \mathrm{~cm}^{-1}$. The characteristic peaks at $2349 \mathrm{~cm}^{-1}$ and $1340 \mathrm{~cm}^{-1}$ represent the absorption peak of $\mathrm{CO}_{2}$, and the absorption peak of $\mathrm{CO}$ was at $2150 \mathrm{~cm}^{-1}$. This indicates that $\mathrm{CO}_{2}$ and $\mathrm{CO}$ are produced in the combustion process of PET and composite materials. Comparing the FTIR of the same component in Figures 9-12, it can be clearly seen that, after the addition of 3\% CMSs-GDP, the characteristic peaks of PET segments are weaker than other composites, which indicates the degradation of PET is significantly reduced.

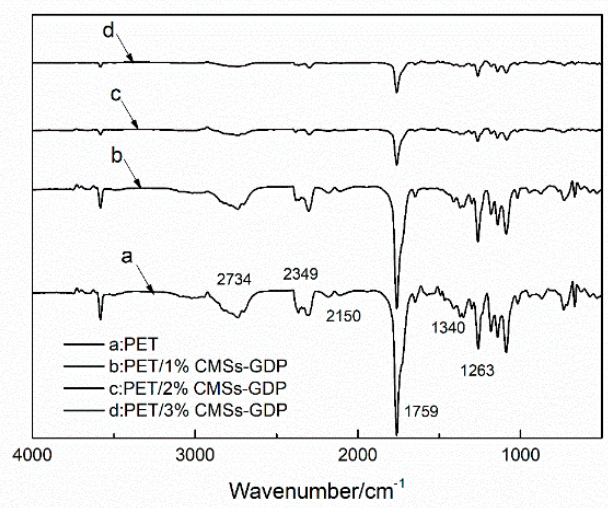

Figure 9. FTIR of pure PET and PET/CMSs composites at decomposition temperature $\left(\mathrm{T}_{5 \%}\right)$.

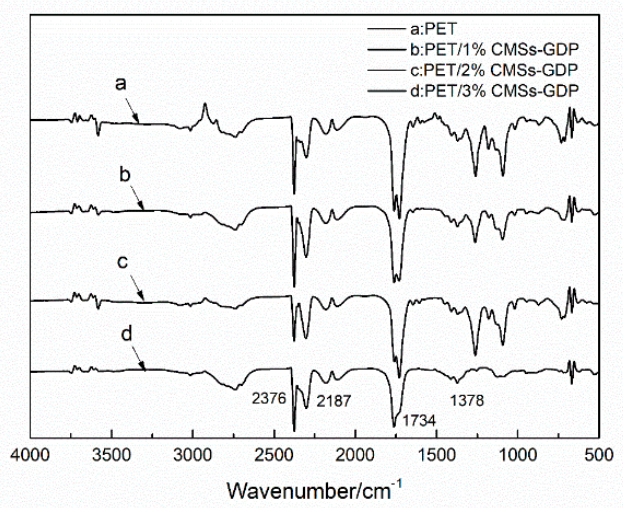

Figure 10. FTIR of PET composites at maximum decomposition temperature $\left(\mathrm{T}_{\max }\right)$.

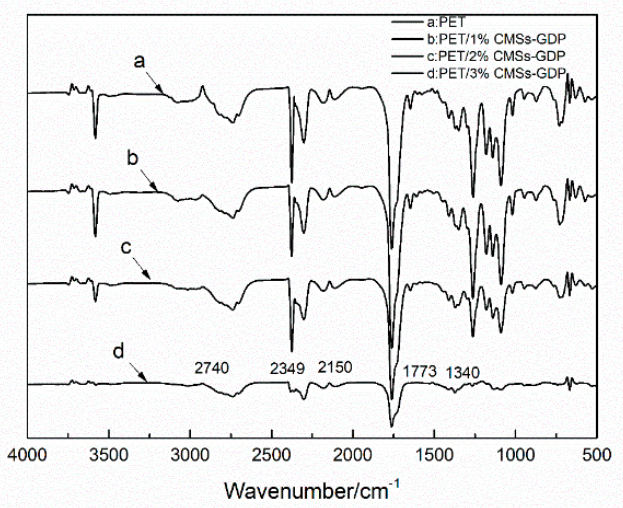

Figure 11. FTIR of PET composite at termination temperature $\left(\mathrm{T}_{95} \%\right)$. 


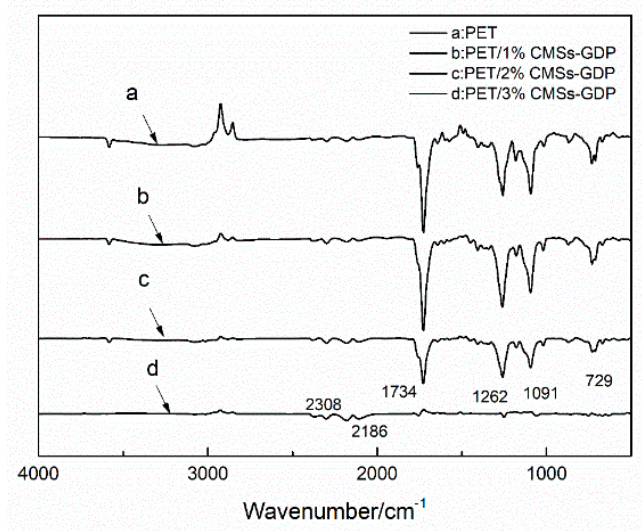

Figure 12. FTIR of PET composite at termination temperature $\left(800^{\circ} \mathrm{C}\right)$.

During the decomposition process, the infrared characteristic peaks of $\mathrm{CO}_{2}\left(2349 \mathrm{~cm}^{-1}, 1340 \mathrm{~cm}^{-1}\right)$ and $\mathrm{CO}\left(2150 \mathrm{~cm}^{-1}\right)$ of pure PET are high. With the addition of CMSs-GDP, the content of $\mathrm{CO}_{2}$ is increased, and the content of $\mathrm{CO}$ is reduced.

It is clearly demonstrated in Figure 13a that the GDP was grafted onto CMSs. The CMSs were coated with GDP, and the CMSs-GDP was incorporated into PET. The consistency of the composite material consisting of grafted CMSs with PET is homogeneous. Figure 13b shows that there are many CMSs with grafted GDP dispersed in the PET material. The dispersion of CMSs was improved, and the combination of CMSs and PET was stable and showed good performance.

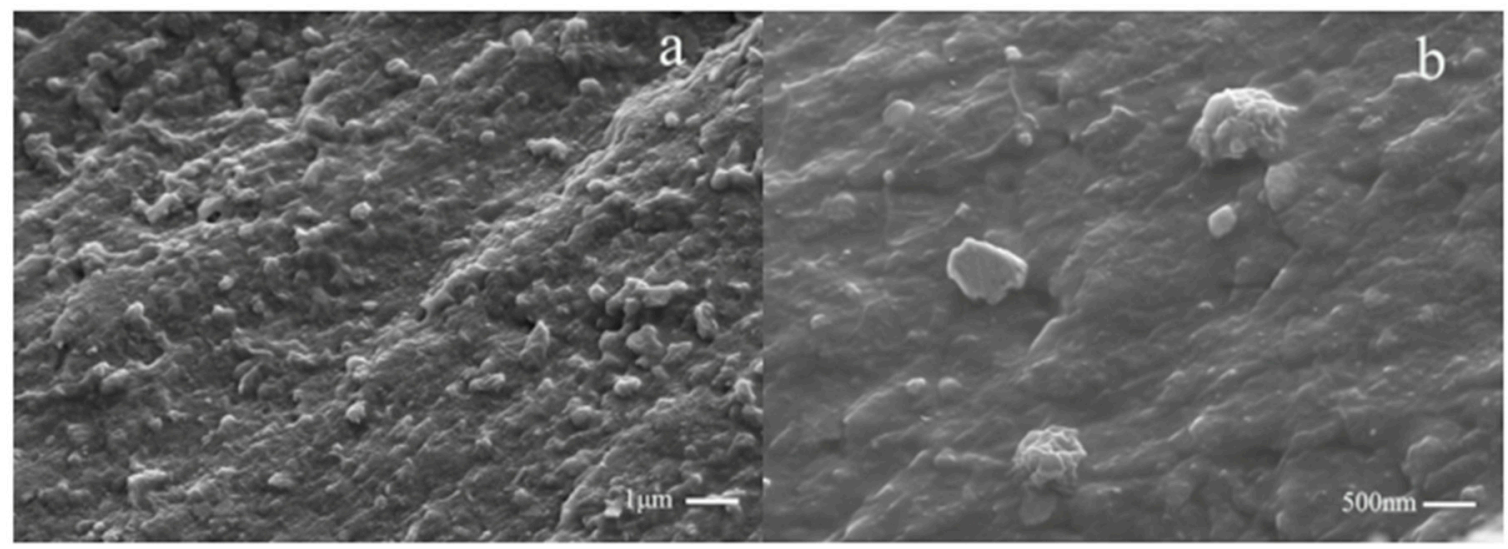

Figure 13. Scanning electron microscope image of PET composite material. (a) CMSs grafted with GDP; (b) CMSs with grafted GDP dispersed in the PET material.

\subsection{Crystallization Performance of PET Composite Material}

Figures 14 and 15 and Table 4 show the DSC data for PET composites. It can be seen from the figure that the introduction of CMSs-GDP can further improve the crystallization ability and crystallization rate of PET composites. The crystallization temperature of pure PET is $164.61{ }^{\circ} \mathrm{C}$ and the crystallinity is $22.27 \%$. With addition of $1 \%$ CMSs-PLS, the crystallization temperature is increased to $209{ }^{\circ} \mathrm{C}$ and the crystallinity is increased to $30.82 \%$. The crystallinity increases with the addition of the amount, and the crystallinity after adding 1\%CMSs-GDP is $36.43 \%$. When 3\% CMSs-GDP is added, the crystallinity of PET $/ 3 \%$ CMSs-GDP is increased to $34.29 \%$, so it can be concluded that the CMSs-GDP is a kind of nucleating agent when combined with PET material. It can significantly increase the crystallinity and crystallization rate of the PET matrix, making it easier to form a network crystal structure. In summary, CMSs-GDP can increase the crystallinity and crystallization rate of the PET and its effect is better than CMSs-PLS. 


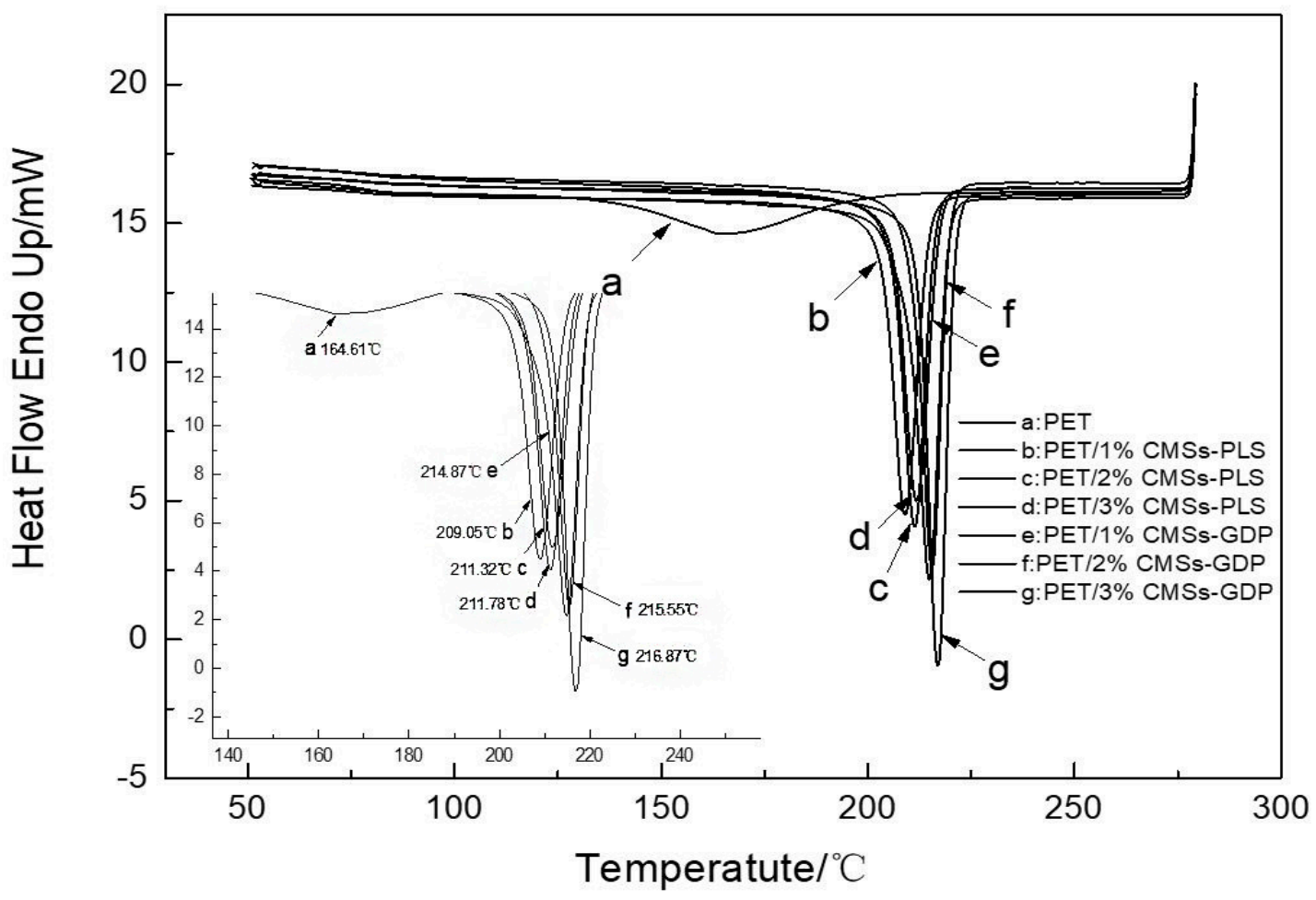

Figure 14. Cooling curve of the PET composite material.

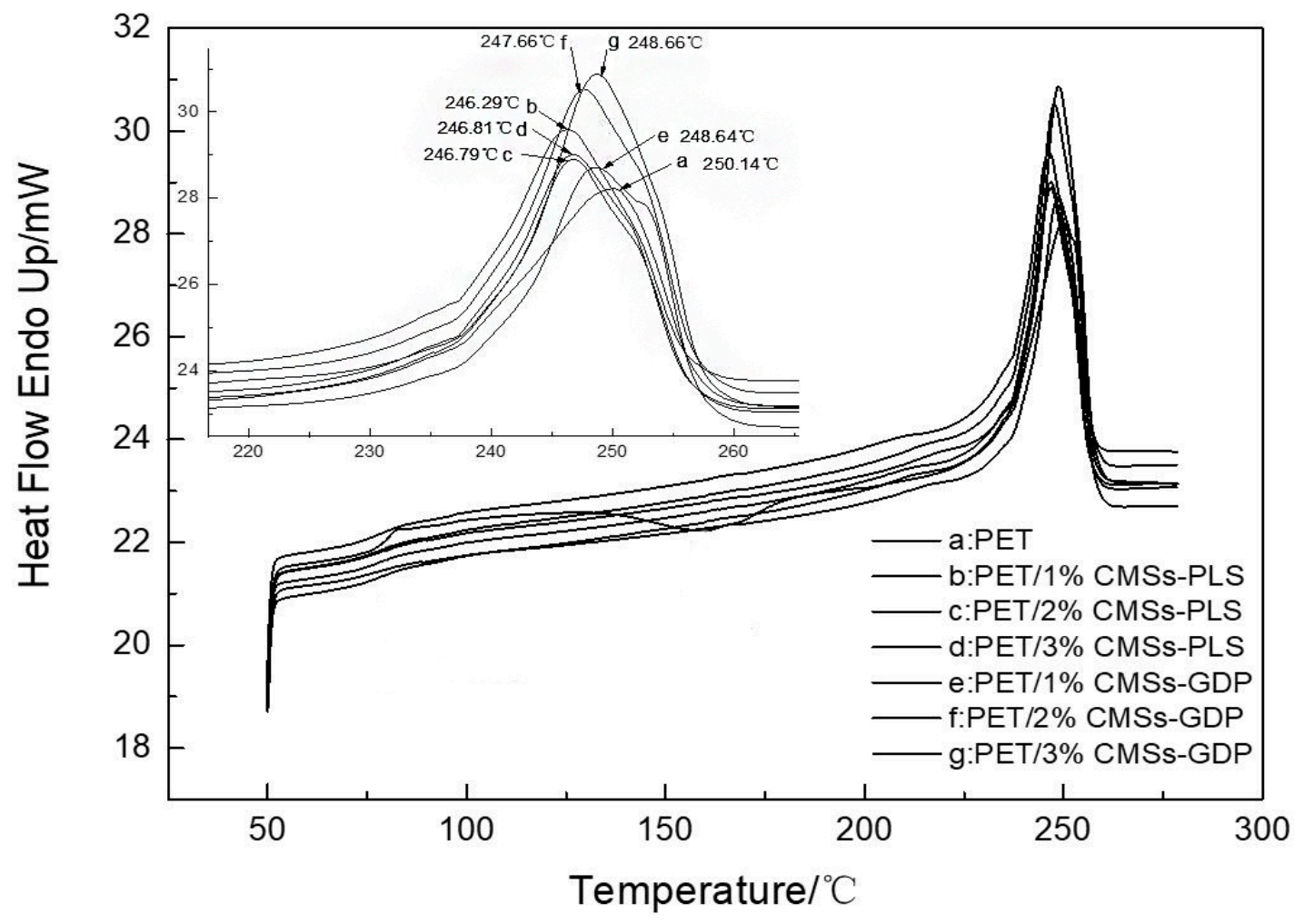

Figure 15. Heating curve of the PET composite material. 
Table 4. DSC data of the PET composite material.

\begin{tabular}{cccccc}
\hline Sample & $\mathbf{T m} /{ }^{\circ} \mathbf{C}$ & $\mathbf{T m c} /{ }^{\circ} \mathbf{C}$ & $\Delta \mathbf{H m} /(\mathbf{J} / \mathbf{g})$ & $\Delta \mathbf{H m c}(\mathbf{J} / \mathbf{g})$ & Crystallinity $/ \%$ \\
\hline PET & 250.14 & 164.61 & 38.90 & 26.06 & 22.27 \\
PET/1\%CMSs-PLS & 246.29 & 209.05 & 43.16 & 45.48 & 30.82 \\
PET/2\%CMSs-PLS & 246.79 & 211.32 & 44.80 & 46.32 & 32.00 \\
PET/3\%CMSs-PLS & 246.81 & 211.78 & 43.35 & 47.33 & 30.96 \\
PET/1\%CMSs-GDP & 248.64 & 214.87 & 51.00 & 49.98 & 36.43 \\
PET/2\%CMSs-GDP & 247.66 & 215.55 & 47.55 & 50.46 & 33.96 \\
PET/3\%CMSs-GDP & 248.66 & 216.87 & 48.00 & 52.29 & 34.29 \\
\hline
\end{tabular}

\subsection{Mechanical Properties of PET Composite Material}

Figure 16 shows that the tensile strength of pure PET is $47.20 \mathrm{MPa}$. With the addition of CMSs, CMSs-PLS, and CMSs-GDP, respectively, the tensile strength of the composite material shows an increasing trend on the whole. The tensile strength of the PET/CMSs-GDP composite material can reach up to $61.20 \mathrm{MPa}$. As a result, the tensile strength of these three different kinds of composites is much higher than that of pure PET. Carbon microspheres can be a nucleating agent (Figure 16), whereby the nucleation of PET is accelerated and the crystallization of PET is promoted, meaning that the chain movement of PET molecules was more difficult and the system tensile strength was significantly improved. However, with an increase in the amount of CMSs, the tensile strength showed a downward trend, and with the increasing crystallization of PET, the density of polar groups in the composite material increased and the material became more brittle. Therefore, the tensile strength of the material decreased.

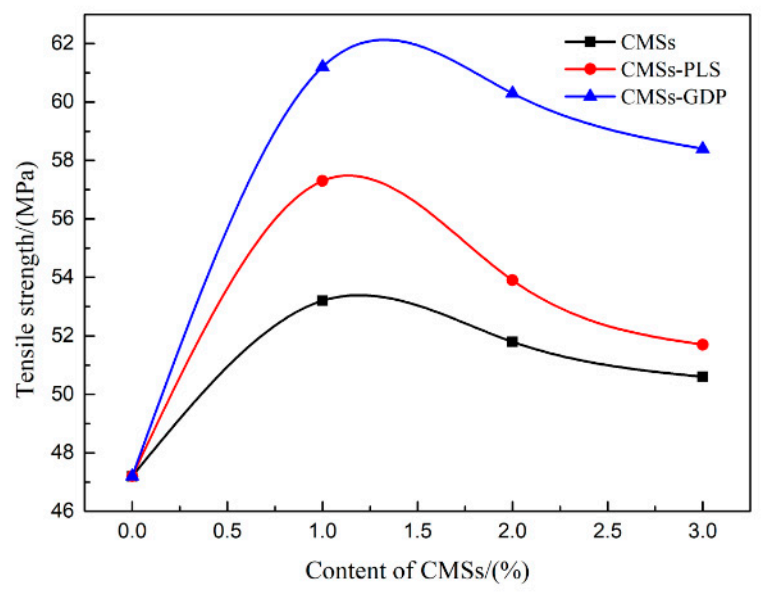

Figure 16. Tensile strength of composite materials.

Figure 17 shows that the elongation of pure PET is $16.85 \%$. With the addition of CMSs, CMSs-PLS, and CMSs-GDP, respectively, the elongation of the composite material shows a decreasing trend on the whole. The elongation at break decreased the most after pure carbon microspheres were added. This is due to the poor dispersibility of carbon microspheres in PET, resulting in a decrease in the chain flexibility of PET. The surface of CMSs modified by low-temperature plasma has hydroxyl and carboxyl groups, so the dispersibility in PET improves, which improves the chain flexibility of PET. Because CMSs-GDP is grafted with guanidine phosphate, the increase in the particle size of the carbon microspheres hinders the chain flexibility of PET, so the elongation at break decreases. 


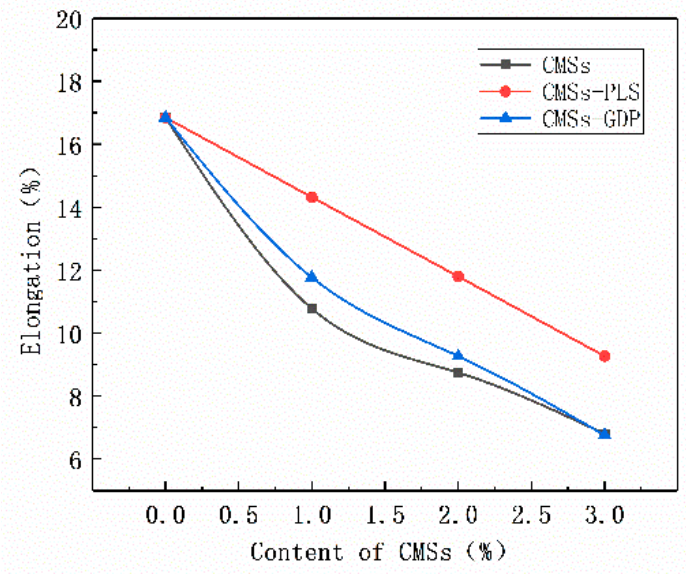

Figure 17. Elongation of composite materials.

\section{Conclusions}

In this study, a series of modified CMSs were successfully synthesized. The effect of the low-temperature plasma technology was shown to have a strong influence on the dispersity of CMSs. The obtained CMSs-PLS shows the best dispersity in polar solvent and the grain size is $\sim 340 \mathrm{~nm}$. The phosphorus-nitrogen flame retardant guanidine phosphate (GDP) was grafted on carbon microspheres (CMSs-GDP) by impregnation, and the obtained CMSs-GDP shows the best flame retardant and thermodynamic properties. The addition of CMSs-GDP as a flame retardant additive has significantly affected the flame retardant of PET composite. With an increase in the amount of CMSs, the flame retardant behavior of the composite material was much more effective. This results in a LOI value of PET/CMSs-GDP composite up to $32.4 \%$ and achieving a UL94-V0 rating. The addition of CMSs-GDP was advantageous to the decomposition of PET; it accelerated the char formation and increased the amount of char residue, resulting in the reduction of the heat transmission from the outside and the fuel gas diffusion from the inside. The non-flammability and high performance of PET/CMSs-GDP were exhibited. For the various types of modified CMSs, the tensile strength of the composite material shows an increasing trend on the whole. The tensile strength of the PET/CMSs-GDP composite material can reach up to $61.20 \mathrm{MPa}$. The addition of CMSs thus has a great influence on the mechanical properties of PET.

Author Contributions: S.J., Q.Y. contributed to the conception of the study; C.J., D.Z. performed the experiment; S.J., C.J., D.Z., contributed significantly to analysis and manuscript preparation; S.J., C.J., D.Z. performed the data analyses and wrote the manuscript; Y.D., D.W. and Q.Y. helped perform the analysis with constructive discussions. All authors have read and agreed to the published version of the manuscript.

Funding: This research was funded by Six Talent Peak Project of Jiangsu Province (TD-XCL-026).

Acknowledgments: This research was funded by Six Talent Peak Project of Jiangsu Province (TD-XCL-026).

Conflicts of Interest: The authors declare no conflict of interest.

\section{References}

1. Levchik, G.F.; Grigoriev, Y.V.; Balabanovich, A.I.; Levchik, S.V.; Klatt, M. Phosphorus-nitrogen containing fire retardants or poly(butylene terephthalate). Polym. Int. 2000, 49, 1095-1100. [CrossRef]

2. Levchik, S.V.; Weil, E.D. A review on thermal decomposition and combustion of thermoplastic polyesters. Polym. Adv. Technol. 2004, 15, 691-700. [CrossRef]

3. Zhang, J.; Ji, Q.; Zhang, P.; Xia, Y.; Kong, Q. Thermal stability and flame-retardancy mechanism of poly(ethylene terephthalate)/boehmite nanocomposites. Polym. Degrad. Stab. 2010, 95, 1211-1218. [CrossRef]

4. Cai, Y.; Guo, Z.; Fang, Z.; Cao, Z. Effects of layered lanthanum phenylphosphonate on flame retardancy of glass-fiber reinforced poly(ethylene terephthalate) nanocomposites. Appl. Clay Sci. 2013, 10, 77-78. [CrossRef] 
5. Wu, Z.; Xue, M.; Wang, H.; Tian, X.; Ding, X.; Zheng, K.; Cui, P. Electrical and flame-retardant properties of carbon nanotube/poly(ethylene terephthalate) composites containing bisphenol A bis(diphenyl phosphate). Polymer 2013, 54, 34-40. [CrossRef]

6. Li, J.; Zeng, X.; Kong, D.; Xu, H. Synergistic effects of a novel silicon-containing triazine charring agent on the flame-retardant properties of poly(ethylene terephthalate)/hexakis (4-phenoxy) cyclotriphosphazene composites. Polym. Compos. 2016, 7, 65-68. [CrossRef]

7. Niu, M.; Wang, X.; Yang, Y.; Hou, W.; Dai, J.; Liu, X.; Xu, B. The structure of microencapsulated carbon microspheres and its flame retardancy in poly(ethylene terephthalate). Prog. Org. Coat. 2016, 3, 79-84. [CrossRef]

8. Frusteri, L.; Cannilla, C.; Bonura, G.; Chuvilin, A.L.; Perathoner, S.; Centi, G.; Frusteri, F. Carbon microspheres preparation, graphitization and surface functionalization for glycerol etherification. Catal. Today 2016, 2, 66-77. [CrossRef]

9. Li, X.; Wu, X. Preparation of multilayer carbon microspheres by using graphitic carbon nitride as precursor. Phys. B Phys. Condens. Matter 2015, 8, 137-140. [CrossRef]

10. Liu, W.; Yang, Y.; Luan, C.; Liu, X.; Xu, B. Thermal stability and surface chemistry evolution of oxidized carbon microspheres. Full. Nanotub. Carb. Nanostruct. 2014, 22, 670-678. [CrossRef]

11. Ma, A.; Wang, X.; Li, T.; Liu, X.; Xu, B. Characteristics of carbon microspheres and study on its adsorption isotherms. Mater. Sci. Eng. A 2007, 443, 54-59.

12. Zhang, Q.; Li, H.; Zhang, P.; Liu, L.; He, Y.; Wang, Y. Surface modification and characterization of carbon spheres by grafting polyelectrolyte brushes. Nanoscale Res. Lett. 2014, 9, 1-6. [CrossRef] [PubMed]

13. Shin, E.S.; Kim, M.S.; Cho, W.I.; Oh, S.H. Sulfur/graphitic hollow carbon sphere nano-composite as a cathode material for high-power lithium-sulfur battery. Nanoscale Res. Lett. 2013, 8, 1-8. [CrossRef] [PubMed]

14. Ryu, J.; Suh, Y.W.; Dong, J.S.; Ahn, D.J. Hydrothermal preparation of carbon microspheres from mono-saccharides and phenolic compounds. Carbon 2010, 48, 990-998. [CrossRef]

15. Yang, Y.; Zhang, Y.; Li, S.; Liu, X.; Xu, B. Grafting molecularly imprinted poly(2-acrylamido-2methylpropanesulfonic acid) onto the surface of carbon microspheres. Appl. Surf. Sci. 2012, 258, 6441-6450. [CrossRef]

16. Yu, L.; Zhu, Y.; Fu, Y. Waxberry-like carbon@polyaniline microspheres with high-performance microwave absorption. Appl. Surf. Sci. 2018, 9, 427-437. [CrossRef]

17. Yang, Y.; Niu, M.; Li, J.; Xue, B.; Dai, J. Preparation of carbon microspheres coated magnesium hydroxide and its application in polyethylene terephthalate as flame retardant. Polym. Degrad. Stab. 2016, 9, 1-9. [CrossRef]

18. Wang, X.; Chen, C.; Zhao, G. Surface modification of carbon nanomaterials by plasma technique and their applications in environmental pollution cleanup. In Abstract Book of China NANO, Proceedings of the International Conference on Nanoscience and Technology, Beijing, China, 5-7 September 2013; National Nanoscience Center: Beijing, China, 2013; pp. 74-75.

19. Meng, J.; Li, X.; Wang, C.; Nie, X.; Dai, Y.; Liu, J.; Xu, H. Surface modification of carbon nanotubes modulate immune response with potential application in tumor immunotherapy. In Abstract Book of the 6th International Conference on Nanoscience \& Technology, Proceedings of the 6th International Conference on Nanoscience E Technology, Beijing, China, 3 September 2013; National Nanoscience Center: Beijing, China, 2013; p. 402.

20. Ling, Y.; Ping, H.; Lu, Q.; Liu, L.; Zhang, Z. Application of Raman spectroscopy in carbon nanotube-based polymer composites. Chin. Sci. Bull. 2010, 55, 3978-3988.

21. Wiacek, J.; Molenda, M. Effect of particle polydispersity on micromechanical properties and energy dissipation in granular mixtures. Particuology 2014, 16, 91-99. [CrossRef]

22. Shin, M.S.; Fard, F.G.; Khatibi, E.; Sarpoolaky, H. Dispersion and stability of carbon black nanoparticles, studied by ultraviolet-visible spectroscopy. J. Taiwan Inst. Chem. Eng. 2009, 3, 524-527.

23. Dai, L.; Wang, L.Y.; Yuan, T.Q.; He, J. Study on thermal degradation kinetics of cellulose graft poly (l-lactic acid) by thermogravimetric analysis. Polym. Degrad. Stab. 2014, 99, 233-239. [CrossRef]

(C) 2020 by the authors. Licensee MDPI, Basel, Switzerland. This article is an open access article distributed under the terms and conditions of the Creative Commons Attribution (CC BY) license (http://creativecommons.org/licenses/by/4.0/). 